\title{
Simplified grading scale for IR breast thermography using as a first-line component of a multi-imaging breast cancer detection strategy
}

\author{
by V. Chernov*, E. Martín-del-Campo-Mena** , G. Chernov***, F. Cirett-Galán****, J. L. Ruiz- \\ Duarte $^{\star * * *}$, R. Torres-Peralta ${ }^{* * *}$ and M.Barboza-Flores* \\ * Departamento de Investigación en Física, Universidad de Sonora, Hermosillo, Sonora 83000, México, \\ chernov@cifus.uson.mx \\ ** Centro Estatal de Cancerología: Miguel Dorantes Mesa, Aguascalientes 100, Progreso Macuiltepetl, Xalapa, \\ Veracruz, 91130, Mexico \\ *** Departamento de Física, Doctorado en Nanotecnología, Universidad de Sonora, Hermosillo, Sonora 83000, \\ Mexico \\ ${ }^{* * *}$ Departamento de Ingeniería Industrial, Universidad de Sonora, Hermosillo, Sonora, Mexico
}

\begin{abstract}
The motivation of the present work is to develop a simple grading scale (mild, moderate or severe) for estimation of an asymmetry level of breast thermograms. The scale should help to distribute test subjects into three groups. The first group, with mild asymmetry, will be supposed to have no thermographic abnormalities. Persons from the second group, moderate asymmetry, will be asked to receive a second thermography exam within 3 to 6 months. The third group, individuals with severe asymmetry, will be referred to oncology doctor and receive the second thermography exam within 2 to 3 months.
\end{abstract}

\section{Introduction}

Infrared (IR) thermography is a unique technology that was approved by the FDA as an adjunct diagnostic breast screening procedure. It can detect early physiologic changes that can be signs of danger in the body years before other tools and offers the opportunity for much earlier detection of cancer. It is a non-invasive, economic, quick diagnostic method that does not touch the patient and does not inflict any pain. There are two possible modalities of breast thermogram processing. The first one is devoted to cancer risk detection/prediction [1], which is based on a score that considers a number of various descriptors extracted from breast thermograms (see, for instance [2]). The second, adjunct screening modality explore the IR imaging as a first-line component of multi-imaging breast cancer detection [3]. Because of a relatively high false-positive rate of IR breast thermography, the multi-imaging modality supposes the testing of suspicious cases by ultrasound, mammography and biopsy exams or/and a second thermography exam to find noticeable changes of abnormality.

In this work we present the results of analysis of the thermal pattern of the breast (anterior view) for a population of symptom-free women aiming to establish normal temperature ranges for five regions of interest (ROls) related to the breast. These ranges were used for identification of hyperthermic and hypothermic areas and for develop the grading scale of the asymmetry level of breast thermograms.

\section{Method}

Two hundred volunteer women with ages ranging from 22 to 85 years (mean age of 48 years) participated in this study. The participants were examined using Flir (SC655, spectral range 7.5-13 $\mu \mathrm{m}$, resolution $640 \times 480$ pixels) or IRIS Elite (spectral range 7.5-13 $\mathrm{mm}$, resolution $320 \times 240$ pixels) digital infrared cameras. The temperature measurements were taken at a distance of about $1 \mathrm{~m}$ in a closed room at $23 \pm 2{ }^{\circ} \mathrm{C}$ and a relative atmosphere humidity of $40-50 \%$.

Preliminary image segmentation was made to separate the body surface from the background. Background pixels with temperatures less than the minimal temperature of the body area were clamped to zero (black in an image). This minimal temperature was defined as a temperature that avoids black areas on the body surface and was found manually. Five ROls: nipples with areolas, breasts, axillary tails, axillas and submammaries were manually selected on the right and left side of the body. The mean temperatures of the body surface $\left(T_{b}\right)$ and $R O$ Ols $\left(T_{i}\right.$, index $i=1-5$ marks $\mathrm{ROI})$ as well as absolute differences $\left(\delta \mathrm{T}_{\mathrm{i}}\right)$ between the right and left body sides together with their standard deviations $\left(\mathrm{SD}_{\mathrm{i}}\right)$ were calculated for each participant.

\section{Results}

The mean temperature of anterior view of body for all participants was found to be in the range of 30.4 and 36.4 ${ }^{\circ} \mathrm{C}$ with average value $\mathrm{T}_{\mathrm{b}, \mathrm{av}}=33.7^{\circ} \mathrm{C}$ and $\mathrm{SD}_{\mathrm{b}, \mathrm{av}}=1.1^{\circ} \mathrm{C}$. The standard deviations of the ROls are in the range of 1.5 
(nipple with areola) and 1.0 (axilla) ${ }^{\circ} \mathrm{C}$. This pronounced spread of the mean temperatures among the participants is related to their individual physiological features. It is possible to reduce the spread of the mean temperatures by calculating them with respect to $T_{b}$. Table 1 presents the differences $\Delta T_{i}=T_{i}-T_{b}$ averaged over the participant population. It is possible to see that the spread of relative mean temperatures is much less than of absolute ones. The relative (with respect to $T_{b}$ ) temperature ranges were used for developing the grading scale of the asymmetry level of breast thermograms. It was assumed that differences between the mean temperatures of right and left body sides of less than $\delta \mathrm{T}_{\mathrm{i}, \mathrm{av}}+1.5 \mathrm{SD}_{\mathrm{\delta i}}$ correspond to mild ROI asymmetry, while the differences higher than $\delta \mathrm{T}_{\mathrm{i}, \mathrm{av}}+3 \mathrm{SD}_{\delta \mathrm{i}}$ correspond to severe ROI asymmetry. The intermediate values of the differences correspond to the moderate ROI asymmetry. The total breast asymmetry level is equal to the ROI asymmetry level with maximal value. Figure 1 shows typical anterior views of breast with selected ROls. The left and right panels show the images with mild and severe asymmetry levels.

The proposed method of evaluation of the asymmetry level of breast thermograms was applied for anterior breast images collected by an oncologist who has specialized in the study of thermography since 2008 [2]. Ninety-eight cases were processed: 77 cases for patients with breast cancer and 21 cases for healthy patients. All the results (either sick or healthy) were confirmed by an open biopsy. It was found that the breast images of almost all patients with cancer exhibit a severe level of asymmetry. The asymmetry level of breast images for healthy patients varied from mild to severe.

\section{REFERENCES}

[1] Etehadtavakol, M., Ng, E.Y.K., "Breast thermography as a potential non-contact method in the early detection of cancer: a review”. J. Mech. Med. Biol. 13, 1330001, 2013.

[2] Cruz-Ramírez, N., Mezura-Montes, E., Ameca-Alducin, M. Y., Martín-Del-Campo-Mena, E., Acosta-Mesa, H. G., Pérez-Castro, N., Guerra-Hernández, A., Hoyos-Rivera, G. and Barrientos-Martínez, R., "Evaluation of the diagnostic power of thermography in breast cancer using bayesian network classifiers. Computational and Mathematical Methods in Medicine, volume 2013, article ID 264246.

[3] Keyserlingk, J.R., Ahlgren, P.D., Yu, E., Belliveau, N., Yassa, M., "Functional infrared imaging of the breast". IEEE Engineering in Medicine and Biology Magazine, 19, 30-41, 2000.

Table 1. The average temperatures of ROls respect to $T_{\text {ant }}$ and average absolute difference between the average temperatures

\begin{tabular}{|l|l|c|c|c|c|c|c|c|c|c|}
\hline \multirow{2}{*}{$\mathrm{i}$} & \multirow{2}{*}{ ROI } & \multicolumn{2}{|c|}{ Right side, ${ }^{\circ} \mathrm{C}$} & \multicolumn{2}{c|}{ Left side, ${ }^{\circ} \mathrm{C}$} & \multicolumn{2}{c|}{ Absolute $\delta \mathrm{T},{ }^{\circ} \mathrm{C}$} & \multicolumn{3}{c|}{ Limit temperature, ${ }^{\circ} \mathrm{C}$} \\
\cline { 3 - 11 } & $\Delta \mathrm{T}_{\mathrm{i}, \mathrm{av}}$, & $\mathrm{SD}_{\mathrm{i}}$ & $\Delta \mathrm{T}_{\mathrm{i}, \mathrm{av}}$ & $\mathrm{SD}_{\mathrm{i}}$ & $\delta \mathrm{T}_{\mathrm{i}, \mathrm{av}}$ & $\mathrm{SD}_{\mathrm{\delta i}}$, & mild & moderate & Severe \\
\hline 1 & Nipple & -1.3 & 0.8 & -1.4 & 0.9 & 0.5 & 0.5 & $<1.2$ & $1.2 \div 2.0$ & $>2.0$ \\
\hline 2 & Breast & -0.5 & 0.4 & -0.5 & 0.4 & 0.3 & 0.2 & $<0.6$ & $0.6 \div 0.9$ & $>0.9$ \\
\hline 3 & Axillary tail & -0.3 & 0.4 & -0.4 & 0.4 & 0.3 & 0.3 & $<0.7$ & $0.7 \div 1.2$ & $>1.2$ \\
\hline 4 & Axilla & 1.0 & 0.7 & 0.9 & 0.8 & 0.3 & 0.4 & $<0.9$ & $0.9 \div 1.4$ & $>1.4$ \\
\hline 5 & Submammary & 1.0 & 0.6 & 1.1 & 0.6 & 0.2 & 0.2 & $<0.6$ & $0.6 \div 1.0$ & $>1.0$ \\
\hline
\end{tabular}
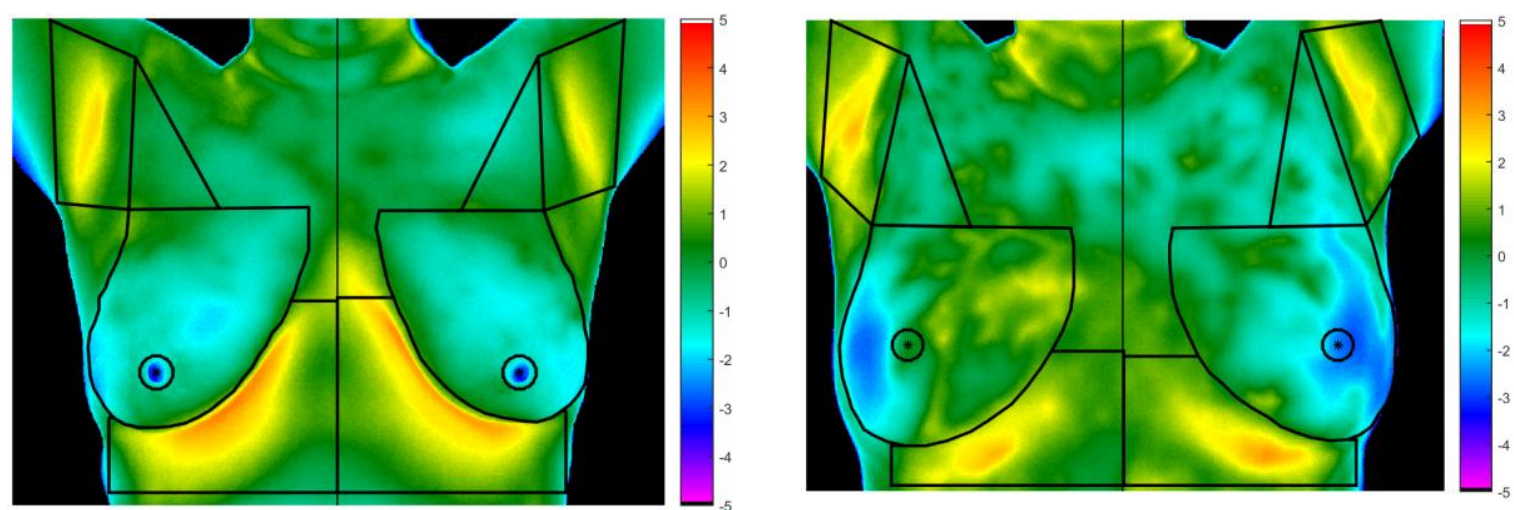

Fig. 1. Thermal breast image (anterior view) of women with mild (left) and severe (right) levels of asymmetry. The black lines limit five ROls on each breast, which are nipples with areolas, breasts, axillary tails, axillas and submammaries. The temperature scales indicate the difference between the surface temperature and the mean temperature of the image (on the body area). 